\title{
Can risky behaviors, gaming addiction, and family sense of coherence accurately classify gender among university students?
}

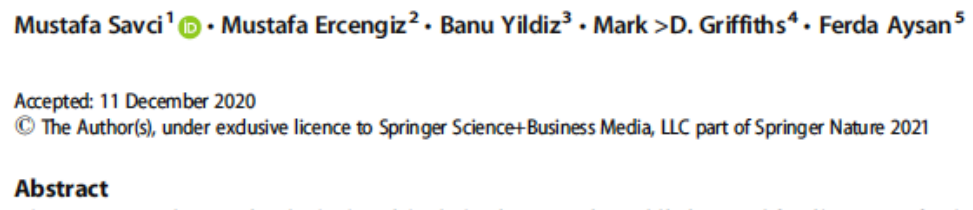

The present study examined whether risky behaviors, gaming addiction, and family sense of coherence classify female and male university students correctly. For this purpose, Logistic Regression Analysis (LRA) was used. The main purpose of LRA is to estimate which group the individual is a member of. LRA is widely used to predict categorical data (i.e., male and female, addicted and non-addicted, single and married). The present study comprised 281 university students (148 females and 133 males) who had been playing digital videogames for at least six months. The measures used included the Risk Behaviors Scale, Digital Game Addiction Scale, and Family Sense of Coherence Scale-Short Form. Analysis demonstrated that risky behavior, gaming addiction, and family sense of coherence predicted gender with $76.5 \%$ accuracy. In other words, risky behaviors, gaming addiction, and family sense of coherence scores can predict a high probability that an individual is male or female. More specifically, risky behaviors (school dropout, antisocial behaviors, alcohol use, smoking, and eating habits) and gaming addiction contributed significantly to the classification of an individual being male or female. The biggest contribution in the classification of gender was digital gaming addiction. Family sense of coherence and risky behaviors such as substance use and suicide tendency did not contribute significantly to gender classification. The present study provided important resulted in terms of demonstrating risk factors related to gender.

\section{Introduction}

Research has shown that there are specific psychosocial aspects relating to human development that occur among emerging adults including those that leave home to study at university. For example, it is during the university years in which social support from the family decreases dramatically (Bernardon et al., 2011) and new social relationships increase (Buote et al., 2007). During this transition period, emerging adults at university have more autonomy to do what they want and when they want which brings both new freedom and new challenges. The present study examines three factors that can come to the fore during this period: risky behaviors, gaming addiction, and family sense of coherence.

There are a number of reasons for examining these three variables among university students. Firstly, research suggests that engaging in risky behaviors and problematic gaming is more common among adolescents aged 13- to 17-years and young adults aged 18- to 22years than among older adults aged 22 years and above (Pharo et al., 2011), due to developmental changes involving desire for sensation seeking and the lack of awareness of potential outcomes in adolescence and young adulthood (Broderick \& Blewitt, 2010; Pharo et 
al., 2011). Secondly, individuals aged between the ages of 16 and 24 years are a risk group for almost all technology-related problematic behavior (e.g., problematic social media use, problematic internet use, problematic smartphone use, problematic gaming; Andreassen et al., 2016; Beard et al., 2017; Mentzoni, et al., 2011; Wu et al., 2015). Thirdly, Antonovsky (1979, 1987) argues that the sense of coherence develops during childhood and early adulthood, and becomes stable at around 30 years of age. Consequently, young adulthood is critical phase in the development of the sense of coherence.

The present study examines risky behaviors, gaming addiction, and family sense of coherence in relation to university students and gender. Powerful analysis is used that predicts gender beyond analysis of differences. Therefore, one or more variables in traditional gender differences analysis cannot predict female or male participants. As a result, we calculate a risk for gender in terms of risky behaviors, gaming addiction, and low level of family sense of coherence.

\section{Gender and risky behaviors}

Risky behaviors are defined as those behaviors that deviate from socially accepted norms and are a threat to those who are engaged in this behavior and those around them (Broderick \& Blewitt, 2010). Risky behaviors include a range of behaviors, such as drinking and driving, risky sexual behavior, truancy, drug use, and vandalism (Broderick et al., 2010).

University transition causes significant changes in the life of young adults with the process of adapting to a new environment. These changes may increase the level of stress and increase the potential for risky behaviors among young adults, and can have destructive physical, psychological, and social consequences (Sohrabivafa et al., 2017). Difficult living conditions such as dormitory life, being away from family, unemployment, lack of suitable recreation facilities, and not meeting emotional needs may also cause risky behavior among 
university students at all stages (i.e., first year to final year) (Sohrabivafa et al., 2017). In addition, gender differences among students may cause different risky behaviors as a way of coping with these difficult living conditions.

When studies investigating risky behaviors on the basis of gender are examined, some research states there is no significant gender difference in terms of high-risk behaviors (e.g., Gardner \& Steinberg, 2005; Rahmati-Najarkolaei et al., 2014). However, there are many studies suggesting that men are more likely to engage in risky behaviors than women (e.g., Cross et al., 2011; Gibbons \& Gerrard, 1995; Gottert et al., 2018; Korn \& Bonny-Noach, 2018; Newmann et al., 2018; Olson et al., 1999; Sohrabivafa et al., 2017). Gibbons and Gerrard (1995) argue that male students' greater emphasis on social impact and their perception of risky behavior being viewed positively by others leads to an increase in this type of behavior.

It has also been suggested that men are more engaged in risky behaviors because they are more impulsive (Cross et al., 2011; Olson et al., 1999). In addition, in accordance with aforementioned studies and based on the Problem Behavior Theory (PBT), Korn and BonnyNoach (2018) point out that men engage in risky behaviors, also conceptualized as stressmaladaptive behaviors, due to their stressful social roles in society such as the need to prove themselves in many ways about their livelihood. When examining gender differences in risky behaviors, it has been noted that the type of risky behavior should be also taken into consideration (Centers for Disease Control, 2010). Based on this, it has been found that men engage in more externalized risky behaviors, such as violence, criminal behavior, and sexual behaviors (Centers for Disease Control, 2010; Korn \& Bonny-Noach, 2018; Sohrabivafa et al., 2017; Thompson et al., 2011), and women tend to engage in more internalized risky behaviors such as self-harm (Zahn-Waxler et al., 2000; Raghibi, 2012). Although there is no consensus regarding gender differences in terms of overall risky behaviors, there is a tendency 
for males to be more at risk. Therefore, it is hypothesized that risky behaviors will accurately predict male gender among university students $\left(\mathrm{H}_{1}\right)$.

\section{Gender and gaming addiction}

The latest (fifth) edition of the Diagnostic and Statistical Manual of Mental Disorders (DSM-5) [American Psychiatric Association (APA), 2013), suggests digital gaming addiction is akin to Internet Gaming Disorder" (IGD). Gaming addiction may pose a higher risk for new university students due to difficulties in adaptating to a new environment and lack of established friend circle (Kanat, 2019). However, it is possible for university students of any age use gaming as a strategy to cope with problems or shortcomings in their lives such as lack of offline friendships, relationship problems, dissatisfaction with their physical appearance and/or low sociability (Männikkö et al., 2015). Therefore, it is important to examine gaming addiction for students at all university levels and by gender.

There are many studies that show significant gender differences in the effect of gaming addiction (Bonanno \& Kommers, 2005; Kanat, 2019; Phillips et al.,1995). Males report that they are more addicted to playing videogames (Bonanno \& Kommers, 2005; Kanat, 2019; Phillips et al., 1995; Saunders et al., 2017). Bonanno and Kommers (2005) state that boys find videogames more attractive and suitable for their natural cognitive processes. Kanat (2019) claims that for the small minority that experience gaming addiction, it can be dangerous at any age. Moreover, one of the main reasons why males devote more time to videogames is their interest in technology and that they are able to immerse themselves and create online virtual identities in online videogames (Kanat, 2019). However, occasional studies such as that by Kim et al. (2008) have found no significant gender differences regarding gaming addiction. 
However, Lopez-Fernandez et al. (2019) point out that although gaming addiction studies generally focus on male gamers, there is an increasing number of female gamers. Female gamers are less associated with videogames due to reasons such as game culture (male-dominated environments), male gender stereotypes (negative expectations regarding gender-based women and belief that aggressive and competitive videogames are masculine activities). In addition, female gamers can use male avatars because online female identity within videogames is seen as vulnerable, which can make female gamers feel invisible (Lopez- Fernandez et al., 2019). Consequently, in the current gaming climate it remains unclear whether female gamers are as vulnerable to gaming addiction as men. The results of the studies are not unanimous when it comes to gender differences in terms of gaming addiction. However, research generally indicates that males are more likely to experience gaming addiction. Therefore, it is hypothesized gaming addiction will be more likely to predict male gender among university students $\left(\mathrm{H}_{2}\right)$.

\section{Gender and family sense of coherence}

The sense of coherence is a concept derived from the Antonovsky's $(1979,1987)$ salutogenic theory. According to Antonovsky (1987), sense of coherence can be applied at both the family level and the individual level. Family sense of coherence is defined as an important factor in shaping and changing the sense of individual coherence (Antonovsky, 1987; Ngai \& Ngu, 2011).

University students can experience high levels of stress due to life changes (such as residence changes, friendship changes) and may be vulnerable to mental health problems such as depression and anxiety. Sense of coherence has an important place in the prevention and improvement of such mental health problems (Kase et al., 2016). Some empirical studies among adult samples emphasize that the sense of coherence develops throughout life (Feldt et 
al., 2003), while other studies point out that individuals with high sense of coherence are relatively stable (Hakanen et al., 2007). Antonovsky (1987) also suggests that the sense of coherence that develops during childhood and adolescence becomes stable at around the age of 30 years. Therefore, the age range in the present study addressed in the present study (1734 years, although most were emerging adults) is important in terms of showing the development stages of the sense of coherence. In summary, based on previous studies, it is considered important to investigate family sense of coherence among university students.

Furthermore, it has been found that the sense of coherence level among males is higher than females (Larsson \& Kallenberg, 1996; Nilsson et al., 2010; Välimäki et al., 2009). The sense of coherence is inversely related to trait anxiety, and females tend to have higher scores on trait anxiety and lower scores concerning psychological wellbeing than males (Larsson \& Kallenberg, 1996). The sense of coherence is also predictive factor in gender because when males and females face stressful situations, men and women tend to use different coping strategies because they are affected by stressors differently (Carmel et al., 1991; Oelofsen \& Richardson, 2006). Moreover, a study Kase et al. (2016) emphasized that to strengthen the sense of coherence, men get social support from friends, and women get social support from family members and other important people. Consequently, although there is no consensus regarding gender differences in terms of family sense of coherence, there is a tendency for males to be more at risk in terms of low level of family sense of coherence. In other words, we think that a high level of family sense of coherence will classify female university students more successfully. Therefore, it is hypothesized that family sense of coherence will predict female gender in university students $\left(\mathrm{H}_{3}\right)$.

When the relevant literature is examined, no study has ever simultaneously investigated all three independent variables examined in the present study. However, there are studies referring to the binary and indirect relationships of these independent variables (e.g., 
Eriksson \& Lindström, 2006; Escobar-Chaves \& Anderson, 2008; Hansson \& Cederblad, 2004; Harlow et al., 1986; Walters, et al., 1986). In the present study, the age range for the sample group is a critical period in terms of development and stabilization of the sense of family coherence (Antonovsky, 1979, 1987). Moreover, studies examining risky behaviors and gaming addiction assert that this period involving young adulthood is overlooked (Kaur, 2014). Consequently, the present study is important in terms of filling the literature gap that exists based on both theory and empirical evidence.

Based on the aforementioned literature, it has been shown that the stress and distress created by the changing conditions of university life for emerging adults is important for all three independent variables examined in the present study. However, as aforementioned, risky behaviors, gaming addiction, and sense of coherence may differ in terms of gender. In addition, and based on the extant literature, it has been demonstrated that assessing the social environment, culture, and ethnic differences to which the individual is attached to is important on the determinant effect of risky behaviors, gaming addiction, and family sense of coherence on gender. Therefore, it is thought that such a study within Turkish society which has collectivist cultural characteristics is important in shedding light for future studies in this area.

Previous studies have addressed gender differences independently in terms of gaming addiction, risky behaviors, and family sense of coherence. However, the present study is the first in which all three variables are examined together in terms of determining gender differentiation, and fills an important gap in the literature. All previous studies have examined how the variables under investigation here are influenced by gender. However, this study examines how these variables predict gender. An examination of the relationship between the gender variable and independent variables is important in terms of associations with individual and ethnic differences, and guiding appropriate measures and interventions for reducing the level of gaming addiction and risky behaviors and enhancing the sense of 
coherence. Consequently, the present study investigated whether risky behaviors, digital gaming addiction, and family sense of coherence have a distinct relationship with gender based on the aforementioned literature.

\section{Methods}

\section{Participants}

The present study comprised 281 university students (148 females and 133 males) who had been playing digital videogames for at least six months. Just over a half of the participants were female (52.7\%). Participants were in the 17-34-year age range (mean $=21.49$ years; SD $=2.49)$. The average daily digital gaming of participants varied between 0.16 and 10 hours (mean $=1.08$ hours, $\mathrm{SD}=1.58)$. Most participants $(89 \%)$ resided in university dormitories or in homes they rented with friends, and $11 \%$ resided with their family or relatives. Most participants stated they were from a nuclear family (87\%) with the remainder from an extended family (13\%). One-fifth of the participants smoked cigarettes (19\%). All of the data were collected from students at Agri İbrahim Cecen University (Turkey).

\section{Materials}

Risk Behaviors Scale (RBS): The RBS was developed by Genctanirim (2014). The RBS comprises 60 items and seven dimensions (antisocial behaviors, smoking, alcohol use, substance use, suicide tendency, eating habits and school dropout). Responses are provided on a Likert-type scale from 1 (never) to 5 (all the time). High scores from the RBS indicate high level risk behaviors. In the present study, the Cronbach alpha coefficients of the RBS ranged from .64 to .94 (antisocial behaviors $=.79$, alcohol use $=.94$, smoking=.91, suicide tendency $=.91$, eating habits $=.83$, school dropout $=.64$, and substance use $=.93$ ). 
Digital Game Addiction Scale (DGAS-7): The DGAS-7 was developed by Lemmens et al. (2009) and adapted into Turkish by Yalcın-Irmak and Erdogan (2015). The scale comprises seven items (a unidimensional scale) and responses are provided on a Likert-type scale from 1 (never) to 5 (always). The higher the score, the greater the risk of digital gaming addiction (Yalcın-Irmak \& Erdoğan 2015). In the present study, the Cronbach's alpha coefficient was .82.

Family Sense of Coherence Scale-Short Form (FSOC-S): The original 26-item FSOC-S was developed by Antonovsky and Sourani (1988), and was subsequently developed into a 12item short-form by Sagy (1998), and adapted to Turkish by Cecen (2007). The 12-item FSOC-S RBS comprises three dimensions (comprehensible, manageable, and meaningful). In the present study, the Cronbach's alpha coefficient was .70.

\section{Procedure and ethics}

In the present study, ethical permission was obtained by the research team's university ethics committee for data collection and the study was carried out in accordance with the Declaration of Helsinki. The aim of the study was explained to the participants, and a written informed consent was provided by all students. The data were collected voluntarily in the classes where the students were being taught. Students' playing of videogames was defined as the key inclusion criterion. Students who did not play videogames and/or declined to participate in the study were excluded. A total of 11 students declined to participate in the study (96.1\% response rate). The data collection process lasted approximately 20 minutes for each participant. 


\section{Data analysis}

The present study examined whether risky behaviors, gaming addiction, and family sense of coherence correctly identified the gender of the participant. For this purpose, Logistic Regression Analysis (LRA) was used. The main purpose of LRA is to estimate which group an individual is a member of. LRA is widely used to predict categorical data (i.e., males and females, addicted and non-addicted, single and married, etc.). In the present study, gender was the variable to be predicted. The predictor variables were risky behaviors, gaming addiction, and family sense of coherence. Before the analysis was performed, the assumptions of LRA were investigated. LRA does not have to meet the assumptions of linear regression models. However, in the LRA, sample size, outlier, and multicollinearity problems need be taken into consideration. Consequently, the dataset was examined in terms of the outliers and no outlier data were identified to negatively affect analyses. In order to achieve consistent resulted in LRA, independent variables (male and female) must be represented by at least 50 participants (Cokluk et al., 2012), therefore, the sample size was large enough for carrying out the analyses. Multicollinearity problems occur when the binary correlation between the variables is greater than .90 , and prevents reliable results. All binary correlation coefficients of the variables were smaller than .90 , therefore, there are no multicollinearity problems in the dataset. Given all these checks, the dataset was deemed suitable for LRA. In LRA, the "enter" method was used. In this method, the common effect of all predictive variables on the dependent variable is examined (Cokluk et al., 2012; Tabachnick \& Fidell, 2013). SPSS 20. Package was used for data analysis. 


\section{Results}

\section{Descriptive statistics and bivariate correlations}

Bivariate correlations (Table 1) show that only family sense of coherence was not significantly statistically associated with some risky behaviors (i.e., alcohol use, eating habits and school dropout). All remaining bivariate correlations were statistically significant.

[Table 1]

\section{LRA Results}

LRA was used to determine the extent to which independent variables (risky behaviors, gaming addiction, and family sense of coherence) could predict gender. First, female students were coded as ' 0 ' and male students are coded as ' 1 '. The analysis was then performed using the aforementioned 'enter' method. The -2log likelihood (-2LL) was examined first. The $-2 \mathrm{LL}$ value is an index of model fit, and the maximum likelihood estimation shows how good the fit is. A -2LL value of " 0 " indicates perfect fit. In other words, the probability is " 1 " in such a case. Two values are calculated related to -2LL in logistic regression analysis. The first of these values belonged to the baseline model (constant-only model). This value relates to the model that contains only constants. The second value of $-2 \mathrm{LL}$ belonged to the objective model (the one formed by modeling the predictive variables). By comparing the two -2LL values, improvement in the model originating from predictive variables can be evaluated (Cokluk et al., 2012). The -2LL value in the baseline model in this research was calculated to be 388.748 .

The predictions of the baseline model were made purely on whichever category occurred most often in the dataset. The model always guesses 'female' because the number of women was more than the number of men in the dataset. In this case, the analysis classifies participants with an arbitrary calculation (Çokluk et al., 2012; Field, 2005). In the present 
study, all participants were classified in the female group with a 52.7\% classification percentage in the baseline model. This ratio was re-calculated by entering the predictive variables into the model. Therefore, the extent to which predictive variables classified the predicted variable was calculated. Results of the baseline model are presented in Table 2 .

[Table 2]

The baseline model includes the constant term, the standard error of the constant term, the Wald statistic, the degree of freedom of the Wald statistic, the level of significance, and the $\operatorname{Exp}(\beta)$ (Exponentiated Logistic Coefficient). To determine whether the variables that are not included in the initial model provide significant contributions to the model, the error chisquare statistic $\left(\chi_{\beta O}^{2}\right)$ can be examined. $\chi_{\beta o}^{2}$ describes the effect of predictive variables to be added to the model on the predictive power of the model. The significance of the $\chi_{\beta o}^{2}$ value $(p<.05)$ indicates that the predictive variables that do not exist in the model will increase the predictive power of the model (Cokluk et al., 2012). In the present study, $\chi_{\beta o}^{2}$ was $86.964(p<.001)$. This indicates that the predictive variables to be added to the model will improve the predictive power of the model. The variables not included in the baseline model and results of related to $\chi_{\beta o}^{2}$ are presented in Table 3 .

\section{[Table 3]}

The score values given in Table 3 and the $p$-values related to these values indicate whether the contribution of predictive variables to the model is significant. The fact that the $\chi_{\beta o}^{2}$ statistic is significant means that the predictive variables will contribute to the model (Cokluk et al., 2012; Field, 2005). Therefore, the predictive variables in this research will increase the predictive power of the model. The $p$-value $(p<.001)$ was found to be significant for $\chi_{\beta o}^{2}$. Score values give information about the contribution of each predictive variable to 
the model. Accordingly, the largest contribution to the model came from the smoking variable. Smoking was followed by gaming addiction, antisocial behaviors, alcohol use, substance use, school dropout, and family sense of coherence. Suicide tendency and eating habits did not contribute significantly to the model.

Up to this point, only the analysis of the baseline model containing the constant term has been presented. In the next analyses, the findings of the model formed by inclusion of predictive variables in the model are presented. This model is called the objective model. In the objective model, the results of the Omnibus Test were examined first. The Omnibus Test calculates the chi-square values in terms of the model, block and step. The calculated chisquare gives information about the difference between the baseline model and the objective model. Significant chi-square values indicate that predictive variables are effective in classifying predicted variables in the objective model. In the present study, the chi-square values for model, block, and step were determined as $108.237(p<.001)$. This value also shows the difference between -2LL in the baseline model and -2LL in the objective model. The value of -2LL calculated as 388,748 in the baseline model was found to be 280,511 in the objective model. -2LL difference between the baseline model and the objective model was calculated as 388.748 minus $280.511=108.237$. The fact that this difference is significant indicates that predictor variables increase the predictive power of the objective model. In the present study, Cox and Snell R Square value was calculated as being .32. This finding indicates that predictor variables explained $32 \%$ of the variance in the predicted variable (being male or female). Following this, the results of the Hosmer and Lemeshow tests were examined. The Hosmer and Lemeshow Test provides general information about the fit of the regression model. The fact that the test result was not significant $(p>.05)$ indicates that the model was consistent with the research data. The fact that the test result was significant $(p<.05)$ indicates that the model was not in agreement with the research data. In 
the present study, the chi-square value for Hosmer and Lemeshow Test was 9.843 $(p>.05)$. The results of the classification obtained as a result of logistic regression model are presented in Table 4.

[Table 4]

As seen in Table $4,81.1 \%$ of the female participants were correctly classified and $71.4 \%$ of the male participants were correctly classified meaning that $76.5 \%$ of the male and female participants were correctly classified. In other words, risky behaviors, gaming addiction, and family sense of coherence predicted gender with $76.1 \%$ accuracy. In the baseline model, the rate was $52.7 \%$.

Finally, the results of Wald statistic were examined. Wald statistics test the significance of logistic regression models and are similar to t-tests in linear regression. In Wald statistics, Beta coefficients are calculated for each predictor variable and the $p$-value is calculated for whether this coefficient is significant (Cokluk et al., 2012). Table 5 presents the coefficient estimates of the variables in the objective model and the Wald statistics.

[Table 5]

As seen in Table 5, a one-unit increase in the school dropout variable resulted in an increase of $12.8 \%$ [(1-1.128) .100] in the odds of being male (male participants are coded as ' 1 '). A one-unit increase in the antisocial behaviors variable resulted in an increase of $7.3 \%$ $[(1-1.073) .100]$ in the odds of being male. A one-unit increase in the alcohol use variable resulted in an increase of $9.5 \%$ [(1-1.095) .100] in the odds of being male. A one-unit increase in the smoking variable resulted in an increase of $8.1 \%[(1-1.081) .100]$ in the odds of being male. A one-unit increase in the eating habits variable resulted in a decrease of 7.7\% [(1-.923) $.100]$ in the odds of being male. A one-unit increase in the gaming addiction variable resulted in an increase of $17.3 \%[(1-1.173) .100]$ in the odds of being male. These findings suggest that variables such as school dropout, antisocial behaviors, alcohol use, smoking, eating habits 
and gaming addiction contribute significantly to the classification of female and male participants. The biggest contribution in the classification of male and female participants belongs to digital gaming addiction. Family sense of coherence and risky behaviors such as substance use and suicide tendency do not contribute significantly to this classification.

\section{Discussion}

Family sense of coherence, risky behaviors, digital gaming addiction, and the interaction of these factors with each other in stressful life events in the context of family relationships are important issues in mental health field. Studies on risky behaviors and gaming addiction often suggest that adolescents and young adulthood are risky age groups due to developmental characteristics, especially males who are a risk group in terms of gender. The results obtained in the present study are discussed in four stages.

First, the findings indicate that risky behaviors (especially school dropout, antisocial behaviors, alcohol use, smoking and eating habits) make important contributions to predicting male gender among university students which confirmed the hypothesis $\left(\mathrm{H}_{1}\right)$. Although there are a few studies in the literature suggesting that risky behaviors are not associated with gender differences (e.g., Gardner \& Steinberg, 2005; Rahmati-Najarkolaei et al., 2014), there are numerous studies showing that men are more likely to engage in risky behaviors (Cross et al., 2011; Gibbons \& Gerrard, 1995; Gottert et al., 2018; Korn \& Bonny-Noach, 2018; Newmann et al., 2018; Olson et al., 1999). The fact that men tend to pay more attention to the social impact of their behavior and behave more impulsively are seen as a possible explanation for the increase in risky behavior compared to women (Cross et al., 2011; Gibbons et al., 1995; Olson et al., 1999). In addition, possible explanations for the higher risk behaviors of men are male's stressful social roles in society (Korn \& Bonny-Noach, 2018), gender related norms, and men's gender role strain (Gottert et al., 2018; Newmann et al., 2018). The results of these studies are similar to the present study's findings. Here, risky 
behaviors such as school dropout, antisocial behaviors, drinking alcohol, smoking cigarettes, and eating habits were determinant of predicting male gender.

Second, the findings indicated that gaming addiction make important contribution to predicting male gender in university students which confirmed the hypothesis $\left(\mathrm{H}_{2}\right)$. When relevant studies are examined, although some researchers suggest that there is no significant difference between male and female gaming addiction (Colwell et al., 1995; Kim et al., 2008), other studies have consistently shown that males are more likely to experience problematic gaming and gaming addiction (Bonanno \& Kommers, 2005; Ekinci et al., 2019; Greenberg et al., 2008; Kanat, 2019; Phillips et al., 1995; Saunders et al., 2017). The possible explanation for these findings are that men are heavier game users than women, gaming is perceived as male activity (Bonanno \& Kommers, 2005; Fox \& Tang, 2014; Kanat, 2019; LopezFernandez et al., 2019), men are more impulsive (Ahrends, 2017), and based on selfdetermination theory, gaming offers the possibility to satisfy basic human needs such as autonomy and competence, particularly among men (Dursun \& Capan, 2018; Reinecke et al., 2012). However, Lopez-Fernandez et al. (2019) note that although gaming addiction studies generally focus on male gamers, there is an increasing number of female gamers. In the present study, it is concluded that there is a significant difference between men and women in terms of gaming dependencies. Therefore, the present study's findings support those of many previous studies.

Third, the findings indicated that the sense of family sense of coherence did not make a statistically significant contribution in classifying female and male university students which did not confirm the hypothesis $\left(\mathrm{H}_{3}\right)$. In the related literature, there are studies noting that the level of men's family sense of coherence is higher than that of women (Larsson \& Kallenberg, 1996; Nilsson et al., 2010; Välimäki et al., 2009), but there are few studies. There are also findings suggesting the predictive role of family sense of coherence on gender is 
associated with different coping styles (Oelofsen \& Richardson, 2006) and different social support resources among men and women (Kase et al., 2016). Therefore, it is necessary to conduct further studies on the predictive power of the family sense of coherence on gender in different sample groups such as various ethnic groups or clinical samples.

Fourth, the study examined the relationships between independent variables (risky behaviors, gaming addiction, and family sense of coherence). Overall, these variables were related to each other in accordance with the extant literature. Such relationships between variables can guide future studies. Therefore, it is important to investigate mediator, moderator, or predictor role relationships between these variables in future studies.

This research is limited due to self-report scales and the convenience sample used. Future research can be supported by qualitative studies by taking opinions of different sample groups and close environment (parents, peers, etc.) for all three variables. Another limitation was that no measures of coping or attachment were included in the survey instrument, therefore only speculative relationships can be made about these non-examined variables. Future studies should include psychometric measures to examine more rigorously the relationships between coping, attachment, and the three variables included in the present study. Finally, another limitation was the Cronbach's alpha coefficient for school dropout (one of the sub-dimensions of the Risky Behavior Scale) which was .64 (i.e., below the accepted .70 value).

\section{Conclusions}

The present study investigated the effects of risky behaviors, digital gaming addiction, and family sense of coherence on gender in a nonclinical and collectivist culture sample. These findings were discussed based in relation to the contemporary literature. While examining the effect of the independent variables on gender, emphasis was also placed on the 
cultural characteristics as well as innate factors. In intervention and prevention studies of risk behaviors and gaming addiction, not only should different gender and cultural characteristics be taken into account, it is also important in therapy to focus on the development of family sense of coherence as an important alternative model in coping with intense stress and lack of self-control which are associated with high levels of risky behavior and digital gaming addiction. It is hoped that the findings obtained from the present study will guide prevention studies in the field of mental health.

Ethics Committee Approval: Ethics committee approval was obtained for this study. The authors report that the study was conducted in accordance with the Helsinki Declaration.

Informed Consent: The Informed Consent Form was read by the researcher in the classroom environment.

Conflict of Interest: No conflict of interest was declared by the authors.

Financial Disclosure: The authors declare that this study received no financial support. 


\section{Reference}

Ahrends, C. (2017). Does excessive music practicing have addiction potential? Psychomusicology: Music, Mind, and Brain,27(3), 191-202. http://dx.doi.org/10.1037/pmu0000188.

American Psychiatric Association (APA). (2013). Diagnostic and Statistical Manual of Mental Disorders (fifth edition). Arlington: American Psychiatric Publishing.

Andreassen, C. S., Billieux, J., Griffiths, M. D., Kuss, D. J., Demetrovics, Z., Mazzoni, E., \& Pallesen, S. (2016). The relationship between addictive use of social media and video games and symptoms of psychiatric disorders: A large-scale cross-sectional study. Psychology of Addictive Behaviors, 30(2), 252-262. http://dx.doi.org/10.1037/adb0000160.

Antonovsky, A. (1979). Health, stress and coping. San Francisco, CA: Jossey-Bass.

Antonovsky, A. (1987). Unraveling the mystery of health. San Francisco, CA: Jossey-Bass.

Antonovsky, A., \& Sourani, T. (1988). Family sense of coherence and family adaption. Journal of Marriage and the Family, 50, 79-92. https://doi.org/10.2307/352429.

Beard, C. L., Haas, A. L., Wickham, R. E., \& Stavropoulos, V. (2017). Age of initiation and internet gaming disorder: The role of self-esteem. Cyberpsychology, Behavior, and Social Networking, 20(6), 397-401. doi: 10.1089/cyber.2017.0011.

Bernardon, S., Babb, K. A., Hakim-Larson, J., \& Gragg, M. (2011). Loneliness, attachment, and the perception and use of social support in university students. Canadian Journal of Behavioural Science/Revue Canadienne Des Sciences Du Comportement, 43(1), 40-51. doi:10.1037/a0021199.

Bonanno, P., \& Kommers, P. A. (2005). Gender differences and styles in the use of digital games. Educational Psychology, 25(1), $13-41$. https://doi.org/10.1080/0144341042000294877. 
Broderick, P. C., \& Blewitt, P. (2010). The life span: Human development for professionals. Pearson.

Buote, V. M., Pancer, S. M., Pratt, M. W., Adams, G., Birnie-Lefcovitch, S., Polivy, J., \& Wintre, M. G. (2007). The importance of friends. Journal of Adolescent Research, 22(6), 665-689. doi:10.1177/0743558407306344.

Carmel, S., Anson, O., Levenson, A., Bonneh, D. Y., \& Maoz, B. (1991). Life events, sense of coherence and health: gender differences on the kibbutz. Social Science \& Medicine, 32(10), 1089-1096. https://doi.org/10.1016/0277-9536(91)90084-P.

Cecen, A. R. (2007). The Turkish version of the Family Sense of Coherence Scale-Short Form (FSOC-S): Initial development and validation. Educational Sciences: Theory \& Practice, 7(3), 1199-1220.

Centers for Disease Control and Prevention (CDC). (2010). Youth risk behavior surveillance - United States, surveillance summaries, 2009. Morbidity and Mortality Weekly Reports, 59 (SS-5). Retrieved from https://www.cdc.gov/mmwr/pdf/ss/ss5905.pdf.

Cokluk, Ö., Sekercioglu, G., \& Buyukozturk, Ş. (2012). Multivariate SPSS and LISREL applications for social sciences. (In Turkish). Ankara: Pegem Publishing.

Colwell, J., Grady, C., \& Rhaiti, S. (1995). Computer games, self-esteem and gratification of needs in adolescents. Journal of Community \& Applied Social Psychology, 5(3), $195-$ 206. https://doi.org/10.1002/casp.2450050308.

Cross, C. P., Copping, L. T., \& Campbell, A. (2011). Sex differences in impulsivity: A metaanalysis. Psychological Bulletin, 137(1), 97-130. http://dx.doi.org/10.1037/a0021591.

Dursun, A., \& Capan, B. E. (2018). Ergenlerde dijital oyun bağımlılığı ve psikolojik ihtiyaçlar. İn̈nü Üniversitesi Eğitim Fakültesi Dergisi,19(2), 128-140. https://doi.org/10.17679/inuefd.336272. 
Ekinci, N. E., Yalcin, I., \& Ayhan, C. (2019). Analysis of loneliness levels and digital game addiction of middle school students according to various variables. World Journal of Education, 9(1), 20-27. Doi: doi: https://doi.org/10.5430/wje.v9n1p20.

Eriksson, M., \& Lindström, B. (2006). Antonovsky's sense of coherence and relation with health: A systematic review. Journal of Epidemiology and Community Health, 60, 376-381. https://dx.doi.org/10.1136/jech.2005.041616.

Escobar-Chaves, S., \& Anderson, C. A. (2008). Media and risky behaviors. Future of Children, 18(1), 147-180. https://doi.org/10.1353/foc.0.0007.

Feldt, T., Leskinen, E., Kinnunen, U., \& Ruoppila, I. (2003). The stability of sense of coherence: Comparing two age groups in a 5-year follow-up study. Personality and Individual Differences, 35(5), 1151-1165. https://doi.org/10.1016/S01918869(02)00325-2.

Field, A. (2005). Discovering statistics using SPSS (2nd ed.). London: Sage.

Fox, J., \& Tang, W. Y. (2014). Sexism in online video games: The role of conformity to masculine norms and social dominance orientation. Computers in Human Behavior, 33, 314-320. https://doi.org/10.1016/j.chb.2013.07.014.

Gardner, M., \& Steinberg, L. (2005). Peer influence on risk taking, risk preference, and risky decision making in adolescence and adulthood: An experimental study. Developmental Psychology, 41(4), 625-635. https://doi.org/10.1037/0012-1649.41.4.625.

Genctanirim, D. (2014). University form of Risk Behaviors Scale: Validity and reliability studies. Journal of Measurement and Evaluation in Education and Psychology, 5(1), 24-34. https://doi.org/10.21031/epod.67191.

Gibbons, F. X., \& Gerrard, M. (1995). Predicting young adults health risk behavior. Journal of Personality and Social Psychology, 69(3), 505- 517. https://dx.doi.org/10.1037/0022-3514.69.3.505. 
Gottert, A., Barrington, C., McNaughton-Reyes, H. L., Maman, S., MacPhail, C., Lippman, S. A., ... \& Pettifor, A. (2018). Gender norms, gender role conflict/stress and HIV risk behaviors among men in Mpumalanga, South Africa. AIDS and Behavior, 22(6), 1858-1869. https://doi.org/10.1007/s10461-017-1706-9.

Greenberg, B., Sherry, J., \& Lachlan, K. (2008). Orientations to video games among gender and age groups. Simulation \& Gaming, 41(2), 238-259. https://doi.org/10.1177/1046878108319930.

Hakanen, J. J., Feldt, T., \& Leskinen, E. (2007). Change and stability of sense of coherence in adulthood: Longitudinal evidence from the Healthy Child study. Journal of Research in Personality, 41(3), 602-617. https://doi.org/10.1016/j.jrp.2006.07.001.

Hansson, K., \& Cederblad, M. (2004). Sense of coherence as a meta-theory for salutogenic family therapy. Journal of Family Psychotherapy, 15(1-2), 39-54. https://doi.org/10.1300/J085v15n01_04.

Harlow, L. L., Newcomb, M. D., \& Bender, P. M. (1986). Depression, self-derogation, substance use, and suicide ideation: Lack of purpose in life as a mediational factor. Journal of Clinical Psychology, 42, 5-21. https://doi.org/10.1002/10974679(198601)42:1<5::AID-JCLP2270420102>3.0.CO;2-9.

Kanat, S. (2019). The relationship between digital game addiction, communication skills and loneliness perception levels of university students. International Education Studies, 12(11). https://doi.org/10.5539/ies.v12n11p80.

Kase, T., Endo, S., \& Oishi, K. (2016). Process linking social support to mental health through a sense of coherence in Japanese university students. Mental Health \& Prevention, 4(3-4), 124-129. https://doi.org/10.1016/j.mhp.2016.05.001.

Kaur, B. (2014). The effects of divorce, attachment, and perception of support on engagement in risky behaviors. Doctoral dissertation. University of La Verne, US. 
Kim, E. J., Namkoong, K., Ku, T., \& Kim, S. J. (2008). The relationship between online game addiction and aggression, self-control and narcissistic personality traits. European Psychiatry, 23(3), 212-218. https://doi.org/10.1016/j.eurpsy.2007.10.010.

Korn, L., \& Bonny-Noach, H. (2018). Gender differences in deviance and health risk behaviors among young-adults undergraduate students. Substance Use \& Misuse, 53(1), 59-69. https://doi.org/10.1080/10826084.2017.1323924.

Larsson, G., \& Kallenberg, K. O. (1996). Sense of coherence, socioeconomic conditions and health: Interrelationships in a nation-wide Swedish sample. European Journal of Public Health, 6(3), 175-180. https://doi.org/10.1093/eurpub/6.3.175.

Lemmens, J. S., Valkenburg, P. M., \& Peter, J. (2009). Development and validation of a Game Addiction Scale for Adolescents. Media Psychology, 12(1), 77-95. https://doi.org/10.1080/15213260802669458.

Lopez-Fernandez, O., Williams, A. J., Griffiths, M. D., \& Kuss, D. J. (2019). Female gaming, gaming addiction, and the role of women within gaming culture: A narrative literature review. Frontiers in Psychiatry, 10, 454. https://doi.org/10.3389/fpsyt.2019.00454.

Männikkö, N., Billieux, J., \& Kääriäinen, M. (2015). Problematic digital gaming behavior and its relation to the psychological, social and physical health of Finnish adolescents and young adults. Journal of Behavioral Addictions, 4(4), 281-288. https://doi.org/10.1556/2006.4.2015.040.

Mentzoni, R. A., Brunborg, G. S., Molde, H., Myrseth, H., Skouverøe, K. J. M., Hetland, J., \& Pallesen, S. (2011). Problematic video game use: Estimated prevalence and associations with mental and physical health. Cyberpsychology, Behavior, and Social Networking, 14(10), 591-596. doi: 10.1089/cyber.2010.0260. 
Newmann, S., Rocca, C., Zakaras, J., Ndunyu, L., Gitome, S., Bukusi, E., \& Dworkin, S. (2018). Men's gender role conflict and contraceptive use: An examination in Kenya. Contraception, 98(4), 358. https://doi.org/10.1016/j.contraception.2018.07.089

Ngai, F. W., \& Ngu, S. F. (2011). Translation and validation of a Chinese version of the Family Sense of Coherence Scale in Chinese childbearing families. Nursing research, 60(5), 295-301. https://doi.org/10.1097/nnr.0b013e3182269b00.

Nilsson, K. W., Leppert, J., Simonsson, B., \& Starrin, B. (2010). Sense of coherence and psychological well-being: improvement with age. Journal of Epidemiology \& Community Health, 64(4), 347-352. http://dx.doi.org/10.1136/jech.2008.081174.

Oelofsen, N., \& Richardson, P. (2006). Sense of coherence and parenting stress in mothers and fathers of preschool children with developmental disability. Journal of Intellectual and Developmental Disability, 31(1), 1-12. https://doi.org/10.1080/13668250500349367.

Olson, S.L., Schilling, E.M., \& Bates, J.E. (1999). Measurement of impulsivity: Construct coherence, longitudinal stability, and relationship with externalizing problems in middle childhood and adolescence. Journal of Abnormal Child Psychology, 27(2), 151-165. https://doi.org/10.1023/A:1021915615677.

Pharo, H., Sim, C., Graham, M., Gross, J., \& Hayne, H. (2011). Risky business: Executive function, personality, and reckless behavior during adolescence and emerging adulthood. Behavioral Neuroscience, 125(6), 970-978. https://dx.doi.org/10.1037/a00 25768 .

Phillips, C. A., Rolls, S., Rouse, A., \& Griffiths, M. D. (1995). Home video game playing in schoolchildren: A study of incidence and patterns of play. Journal of Adolescence, 18(6), 687-691. https://doi.org/10.1006/jado.1995.1049. 
Raghibi, M. (2012). Examining high risk behaviors among students of Zahedan universities. International Journal of High Risk Behaviors and Addiction, 1(1), 39-43. doi: $10.5812 / \mathrm{ijhrba.4188.}$

Rahmati-Najarkolaei, F., Kamalikhah, T., Goldoust-Marandy, F., \& Mohammadreza, J. (2014). The comparative health-risk behaviors between boys and females of freshmen at university of Tehran, Iran. Iranian Journal of Health Sciences, 2, 15-23. 10.18869/acadpub.jhs.2.3.15.

Reinecke, L., Tamborini, R., Grizzard, M., Lewis, R., Eden, A., \& David Bowman, N. (2012). Characterizing mood management as need satisfaction: The effects of intrinsic needs on selective exposure and mood repair. Journal of Communication, 62(3), 437-453. https://doi.org/10.1111/j.1460-2466.2012.01649.x.

Sagy, S. (1998). Effects of personal, family and community characteristics of emotional reactions in a stress situation: The Golan Heights negotiations. Youth and Society, 29(3), 311-329. https://doi.org/10.1177/0044118x98029003003.

Saunders, J. B., Hao, W., Long, J., King, D. L., Mann, K., \& Fauth-Buhler, M. (2017). Gaming disorder: its delineation as an important condition for diagnosis, management, and prevention. Journal of Behavioral Addictions, 6(3), 271-9.

Sohrabivafa, M., Tosang, M. A., Zadeh, S. Z. M., Goodarzi, E., Asadi, Z. S., Alikhani, A., ... \& Khazaei, Z. (2017). Prevalence of risky behaviors and related factors among students of Dezful. Iranian Journal of Psychiatry, 12(3), 188.

Tabachnick, B. G., \& Fidell, L. S. (2013). Using multivariate statistics (sixth edition). New Jersey: Pearson Education.

Thompson, R., Tabone, J. K., Litrownik, A. J., Briggs, E. C., Hussey, J. M., English, D. J., \& Dubowitz, H. (2011). Early adolescent risk behavior outcomes of childhood 
externalizing behavioral trajectories. Journal of Early Adolescence, 31(2), 234-257. https://doi.org/10.1177/0272431609361203.

Välimäki, T. H., Vehviläinen-Julkunen, K. M., Pietilä, A. M. K., \& Pirttilä, T. A. (2009). Caregiver depression is associated with a low sense of coherence and health-related quality of life. Aging and Mental Health, 13(6), 799-807. https://doi.org/10.1080/13607860903046487.

Walters, L. H., Walters, J., \& McKenry, P. C. (1986). Differentiation of girls at risk of early pregnancy from the general population of adolescents. Journal of Genetic Psychology, 142, 19-29. https://doi.org/10.1080/00221325.1987.9914533.

Wu, C.-Y., Lee, M.-B., Liao, S.-C., \& Chang, L.-R. (2015). Risk Factors of Internet Addiction among Internet Users: An Online Questionnaire Survey. Plos One, 10(10), e0137506. doi:10.1371/journal.pone.0137506.

Yalcın-Irmak, A., \& Erdoğan, S. (2015). Validity and reliability of the Turkish version of the Digital Game Addiction Scale. Anatolian Journal of Psychiatry, 16(1), 10-18. https://doi.org/10.5455/apd.170337.

Zahn-Waxler, C., Klimes-Dougan, B., \& Slattery, M. J. (2000). Internalizing problems of childhood and adolescence: Prospects, pitfalls, and progress in understanding the development of anxiety and depression. Development and Psychopathology, 12(3), 443-466. https://doi.org/10.1017/S0954579400003102. 
Table 1. Descriptive statistics and bivariate correlations among variables

\begin{tabular}{|c|c|c|c|c|c|c|c|c|c|}
\hline & 1 & 2 & 3 & 4 & 5 & 6 & 7 & 8 & 9 \\
\hline 1. Antisocial behaviors & 1 & & & & & & & & \\
\hline 2. Alcohol use & $.49^{* *}$ & 1 & & & & & & & \\
\hline 3. Smoking & $.39^{* *}$ & $.43^{* *}$ & 1 & & & & & & \\
\hline 4. Eating habits & $.29^{* *}$ & $.25^{* *}$ & $.32^{* *}$ & 1 & & & & & \\
\hline 5. School dropout & $.39^{* *}$ & $.27^{* *}$ & $.31^{* *}$ & $.38^{* *}$ & 1 & & & & \\
\hline 6. Substance use & $.49^{* *}$ & $.64^{* *}$ & $.47^{* *}$ & $.31^{* *}$ & $.39^{* *}$ & 1 & & & \\
\hline 7. Suicide tendency & $.39^{* *}$ & $.23^{* *}$ & $.29^{* *}$ & $.36^{* *}$ & $.30^{* *}$ & $.31^{* *}$ & 1 & & \\
\hline 8. Gaming addiction & $.41^{* *}$ & $.29^{* *}$ & $.32^{* *}$ & $.30^{* *}$ & $.28^{* *}$ & $.33^{* *}$ & $.34^{* *}$ & 1 & \\
\hline 9.Family sense of coherence & $-.28^{* *}$ & -.08 & $-.13^{*}$ & -.02 & -.09 & $-.15^{* *}$ & $-.42^{* *}$ & $-.13^{*}$ & 1 \\
\hline Range & 33 & 36 & 32 & 32 & 16 & 36 & 48 & 60 & 22 \\
\hline Mean & 18.5 & 11.49 & 17.06 & 21.32 & 8.78 & 12.02 & 26.86 & 59.67 & 13 \\
\hline SD & 5.75 & 5.98 & 8.93 & 6.73 & 3.65 & 5.97 & 10.04 & 10.58 & 5.07 \\
\hline Skewness & 1.07 & 2.94 & 1.00 & .28 & .53 & 2.99 & .77 & -.25 & .79 \\
\hline Kurtosis & 1.4 & 8.96 & -.20 & -.16 & -.36 & 10.61 & .35 & -.16 & -.10 \\
\hline
\end{tabular}


Table 2. Results of the Baseline Model

\begin{tabular}{lcccccc}
\hline Step 0 & $\beta$ & $\begin{array}{c}\text { Standard } \\
\text { Error }\end{array}$ & Wald & df & p & Exp ( $\beta)$ \\
\hline Constant & -.107 & .119 & .800 & 1 & .371 & .899 \\
\hline
\end{tabular}


Table 3. The variables not Included in the baseline model and results related to $\chi_{\beta o}^{2}$

\begin{tabular}{clccc} 
& & Score & df & $p$ \\
\hline & School dropout & 18.704 & 1 & $<.001$ \\
& Antisocial behaviors & 32.447 & 1 & $<.001$ \\
& Alcohol use & 28.029 & 1 & $<.001$ \\
Step 0 & 40.794 & 1 & $<.001$ \\
& Smoking & .230 & 1 & $>.05$ \\
& Eating habits & 24.691 & 1 & $<.001$ \\
& Substance use & 1.228 & 1 & $>.05$ \\
& Suicide tendency & 38.505 & 1 & $<.001$ \\
& Gaming addiction & 6.943 & 1 & $<.01$ \\
\hline Family sense of coherence & 86.964 & 9 & $<.001$ \\
\hline
\end{tabular}


Table 4. Findings related to classification

\begin{tabular}{|c|c|c|c|c|}
\hline \multirow[b]{3}{*}{ Observe } & & \multicolumn{3}{|c|}{ Predicted } \\
\hline & & \multicolumn{2}{|c|}{ Gender } & \multirow{2}{*}{$\begin{array}{c}\text { Percentage } \\
\text { Correct }\end{array}$} \\
\hline & & Female & Male & \\
\hline \multirow{2}{*}{ Step 1} & Female & 120 & 28 & 81.1 \\
\hline & Male & 38 & 95 & 71.4 \\
\hline \multicolumn{2}{|c|}{ Overall Percentage } & & & 76.5 \\
\hline
\end{tabular}


Table 5. Efficient estimates of the variables in the objective model and the Wald statistics

\begin{tabular}{|c|c|c|c|c|c|c|c|}
\hline & & $\mathrm{B}$ & S.E. & Wald & Df & Sig. & $\operatorname{Exp}(B)$ \\
\hline \multirow{9}{*}{ Step $1^{\mathrm{a}}$} & School dropout & .120 & .048 & 6.260 & 1 & $<.05$ & 1.128 \\
\hline & Antisocial behaviors & .071 & .033 & 4.527 & 1 & $<.05$ & 1.073 \\
\hline & Alcohol use & .091 & .042 & 4.607 & 1 & $<.05$ & 1.095 \\
\hline & Smoking & .077 & .021 & 14.254 & 1 & $<.001$ & 1.081 \\
\hline & Eating habits & -.081 & .027 & 8.827 & 1 & $<.01$ & .923 \\
\hline & Substance use & .015 & .041 & .124 & 1 & $>.05$ & 1.015 \\
\hline & Suicide tendency & -1.824 & 1.422 & 1.645 & 1 & $>.05$ & .161 \\
\hline & Gaming addiction & .160 & .036 & 19.313 & 1 & $<.001$ & 1.173 \\
\hline & Family sense of coherence & -.029 & .016 & 3.147 & 1 & $>.05$ & .972 \\
\hline
\end{tabular}

a. Variable(s) entered on step 1: School dropout, antisocial behaviors, alcohol use, smoking, eating habits, substance use, suicide tendency, gaming addiction, family sense of coherence 